\title{
Comparative kinetic analysis of isothermal extraction of caffeine from guarana seed under conventional and microwave heating
}

\author{
Borivoj Adnadjevic $^{a, *}$, Biljana Koturevic ${ }^{b}$, Jelena Jovanovic ${ }^{a}$ \\ a Faculty of Physical Chemistry, University of Belgrade, Studentski trg 12-16, Belgrade 11001, Serbia \\ b The Academy of Criminalistic and Police Studies, Cara Dusana 196, 11080 Belgrade, Zemun, Serbia
}

\section{A R T I C L E I N F O}

\section{Article history:}

Received 11 August 2016

Received in revised form 3

December 2016

Accepted 7 December 2016

Available online 15 December 2016

Keywords:

Caffeine

Conventional extraction

Guarana

Kinetics

Microwave extraction

\begin{abstract}
A B S T R A C T
The kinetics of the isothermal extraction of caffeine from the guarana seed powder with water under conventional $(\mathrm{CH})$ and microwave heating $(\mathrm{MWH})$ were investigated. By applying the isoconversional method, it was established that the kinetics of the caffeine extraction under $\mathrm{CH}$ and also under MWH is an elementary kinetic process. The model fitting method was used to determine the kinetics model of caffeine extraction. It was found that the kinetics of the caffeine extraction for both heating modes can be described by the Jander's equation. The rate of the extraction of caffeine under MWH is $\sim 2$ times higher than under $\mathrm{CH}$. The values of kinetics parameters $\left(E_{\mathrm{a}}\right.$ and $\left.\ln \mathrm{A}\right)$ of the extraction process under $\mathrm{MWH}$ are lower than for $\mathrm{CH}$. The established influence of $\mathrm{MWH}$ on the kinetics of caffeine extraction is explained with a specific activation mechanism of water molecules and with an increase in the energy of the ground vibration level of resonant oscillator of $\mathrm{N}_{3}-\mathrm{CH}_{3}$ band of caffeine molecule $\left(v=317 \mathrm{~cm}^{-1}\right)$ which is caused by the absorption of microwave energy.

๑ 2016 Institution of Chemical Engineers. Published by Elsevier B.V. All rights reserved.
\end{abstract}

\section{Introduction}

Caffeine (1,3,5-trimethylxanthine) is an alkaloid with widespread occurrence in a variety of plants, such as: coffee, tea, mate, cola nuts, cocoa and guarana. Caffeine is a valuable substance for pharmaceutical, food and cosmetics industries, which acts as stimulant for the heart, respiratory and the central nervous system, and is a vasodilator and a diuretic (Jun, 2009). The amount of caffeine found in plants varies, with the highest amounts found in guarana (Paullinia cupana, Sapindaceae), that can be up to $7.5 \%$ (Beck, 2005), which makes guarana a useful raw material for the extraction of caffeine.

Extraction of caffeine from various plants was abundantly investigated, focusing mainly on conventional solvent extraction, using either pure solvents (water, methylene chloride, and chloroform) or water-organic solvent mixtures (Wang and Helliwell, 2000). These methods have some disadvantages since they are time-consuming and result in low extraction yields.

In recent years, more advanced extraction methods have been used as an alternative to conventional solvent extractions of caffeine. These methods include ultrasound-assisted extraction (Rostagno et al., 2011; Sereshti et al., 2013); supercritical fluid extraction (Mehr et al., 1996; Saldaña et al., 2002; Tello et al., 2011); solid-phase extraction (Jafari et al., 2011); dispersive liquid-liquid extraction (Sereshti and Samadi, 2014); pressure processing assisted extraction (Jun, 2009); extraction using battery type extractor (Senol and Aydin, 2006); and column-chromatography extraction (Wang et al., 2012). Among these advanced methods, considerable attention in recent years has been focused on microwave-assisted extraction (MAE).

\footnotetext{
* Corresponding author.

E-mail addresses: bora@ffh.bg.ac.rs, biljanakoturevic@gmail.com (B. Adnadjevic). http://dx.doi.org/10.1016/j.cherd.2016.12.006

0263-8762/@ 2016 Institution of Chemical Engineers. Published by Elsevier B.V. All rights reserved.
} 
MAE is a process that uses microwave energy and solvents to extract target compounds from various matrices (Spigno and De Faveri, 2009). When used for the extraction of biologically active compounds from plant materials, MAE has shown many advantages over the conventional extraction method featuring as it can reduce the time of isolation analyte, requires less volume of solvents and produces higher extraction yields (Kaufmann and Christen, 2002). The effect of microwave heating on the kinetics of chemical reaction and physicochemical processes is explained as combination of the thermal effect (overheating, hot spots and selective heating) and specific microwave effects (Hoz et al., 2005).

Many reports have been published on the application of MAE of various bioactive compounds from plants, such as: saponins, anthraquinones, flavonoids, and chlorogenic acid (Chen et al., 2007; Hemwimon et al., 2007; Xiao et al., 2008; Zhang et al., 2008). MAEs of caffeine have also been reported, from various teas (Rahim et al., 2014; Lou et al., 2012; Vuong et al., 2012; Wang et al., 2011; Pan et al., 2003) and from cacao (González-Nuñez and Cañizares-Macías, 2011).

Considering findings that the MAE can be effective at extracting bioactives from plant materials, in some papers a comparison of MAE has been made with conventional extraction systems. Pan et al. (2003) and Vuong et al. (2012), investigated the effect of non-isothermal microwave heating on the caffeine extraction from tea and find that microwave irradiation improved caffeine extraction compared to the conventional extraction.

Despite findings that microwave heating can improve extraction of caffeine, there is no literature data about investigations of the kinetics of the isothermal MAE of caffeine. However, the kinetics of the non-isothermal MAE of total phenols and caffeine from black tea powder was studied in the work of Spigno and De Faveri (2009). The effects of microwave power $(450 \mathrm{~W}-900 \mathrm{~W})$ and irradiation time $(30 \mathrm{~s}-210 \mathrm{~s})$ on the degree of extraction of total phenols using an ordinary household microwave oven were investigated.

The kinetics of conventional extraction of caffeine from various plants has been studied extensively. The kinetic model that is usually used for the interpretation of experimental extraction data is the steady state kinetic model, proposed by Spiro and Jago (1982). This model was used by Spiro et al. (1992) and Jaganyi and Price (1999) for describing the conventional extraction of caffeine from tea, and it was established that the concentration of caffeine with time follows firstorder kinetics. Other approaches to model the extraction of various compounds from plants include second-order kinetic model (Pan et al., 2012; Rakotondramasy-Rabesiaka et al., 2007), and combined second-order-diffusional kinetics model (Linares et al., 2010). Besides these expressions, the kinetic models that are frequently used for the interpretation of extraction data are mathematically derived from Fick's second law, as was shown by Stapley (2002) and Ziaedini et al. (2010). Some simplified models derived from Fick's law like the film theory (Stanković et al., 1994), and unsteady state diffusion through plant material (Ponomaryov, 1976; Veličković et al., 2006; Stanisavljević et al., 2007) are also used. Furthermore, for modeling the extraction kinetics, empirical models like Peleg model (Peleg, 1988; Boussetta et al., 2011) and empirical equation of Ponomaryov (Veličković et al., 2006) were also proposed.

To the best of our knowledge, there is no report on the kinetics of the isothermal microwave-assisted extraction of caffeine nor its comparison with kinetics of the conventional extraction technique. Considering the fact that the kinetics of extraction under microwave heating was mainly investigated under non-isothermal conditions, the aim of this work was to impartially determine the influence of microwave heating on the kinetics of extraction. The objective of this work is to perform a comparative analysis of the kinetics of the isothermal extraction of caffeine from guarana seed powder with water under the conventional and microwave heating. The degree of kinetic complexity, kinetic model and kinetic parameters (activation energy $\left(E_{\mathrm{a}}\right)$ and pre-exponential factor $(\ln A)$ ) for both extraction techniques were investigated. Based on the obtained results, formulation of model mechanism of the extraction of caffeine from solid particles of guarana under conventional and microwave conditions is suggested.

\section{Materials and methods}

\subsection{Materials and reagents}

Powdered guarana seeds (Moisture content 7.8\%) with particle size $(\mathrm{dp} \leq 250 \mu \mathrm{m})$ were purchased from a grocery store in Brazil.

Hydrochloric acid (36\%) (p.a.) and sulphuric acid (98\%) (p.a.) were supplied from Zorka Pharma (Šabac, Serbia). Lead acetate anhydrous ( $\geq 33 \%$ basic $\mathrm{Pb}$ as $\mathrm{PbO}$ ) (p.a.) was supplied from Carlo Erba (Milano, Italy).

\subsection{Guarana extraction}

\subsubsection{Conventional extraction of caffeine from guarana}

In a typical experiment, $1 \mathrm{~g}$ of guarana seed powder was suspended in $80 \mathrm{~mL}$ of distilled water which was preheated to a predetermined temperature in a round-bottom flask. The suspension was stirred continuously with a magnetic stirrer at $410 \mathrm{rpm}$ (IKA, RCT basic, Germany) maintaining constant temperature at $313 \mathrm{~K}, 323 \mathrm{~K}, 333 \mathrm{~K}$, and $343 \mathrm{~K}( \pm 1 \mathrm{~K})$. At predominated time intervals, aliquots were taken from reaction mixture, quickly cooled down with an ice bath and filtered through Munktell No. 8 filter paper, (Munktell, Grycksbo, Sweden). All the extractions were performed in triplicate and average value has been reported in the figures.

\subsubsection{Microwave-assisted extraction of caffeine from guarana}

The microwave extraction was carried out in a commercially single-mode microwave device (Discover, CEM Corporation, Matthews, North Carolina, USA), operating at $2.45 \mathrm{GHz}$ with adjustable microwave power output (from 0 to $300 \mathrm{~W}$ ). Distilled water $(80 \mathrm{~mL})$ was placed in a borosilicate vessel (roundbottom flask, designed for microwave reactor) and guarana seed powder $(1.0 \mathrm{~g})$ was added.

The suspension was stirred continuously maintaining constant temperature at $313 \mathrm{~K}, 328 \mathrm{~K}$, and $333 \mathrm{~K}$ in a microwave reactor. At predominated time intervals, aliquots were taken from the reaction mixture, and further treatment were carried out as described above.

The temperature of the extraction mixture was monitored using a calibrated thermometer (fiber-optic probe) inserted into the microwave device. The temperature, power and profiles were monitored using a commercially available software provided by the manufacturer of the microwave device. The used microwave device was modified to maintain automatically required temperature in the reaction system with rapid variations in input power and/or with a change in the flow of 


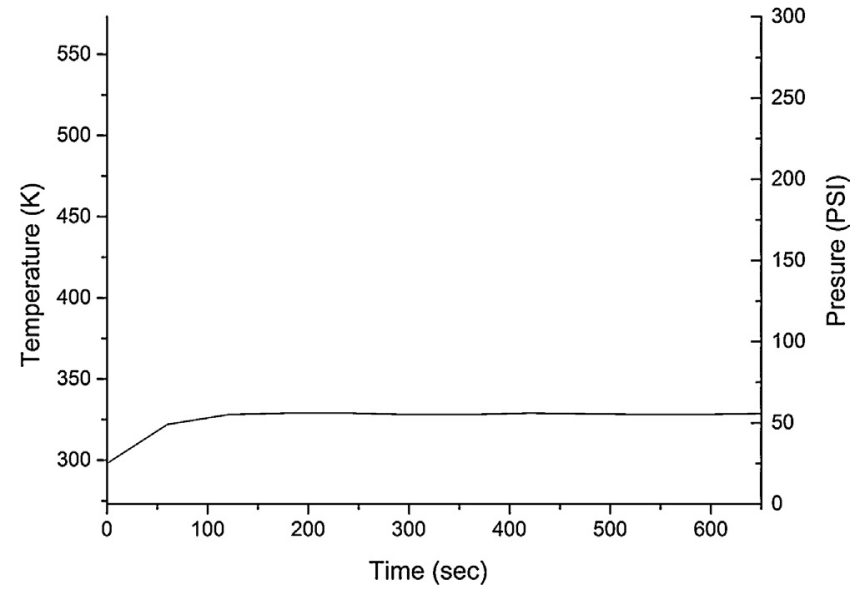

Fig. 1 - Temperature variation in microwave reactor during extraction.

cooled $\mathrm{N}_{2}$ through the heat exchanger immersed in the reactor. When the sensor of the instrument detects a decrease in the temperature of the reaction system related to it, the input power of the microwave field is automatically increased and $\mathrm{N}_{2}$ flow is decreased, and conversely, when there is an increase in the temperature of the reacting system, the input power of the microwave field is automatically decreased and $\mathrm{N}_{2}$ flow is increased in order to achieve the desired temperature of the reacting system.

As can be seen from Fig. 1, after the first $60 \mathrm{~s}$, temperature in the reactor was maintained at a constant value of $328 \pm 1 \mathrm{~K}$, which indicates that satisfactory conditions for studying the isothermal extraction of caffeine were achieved.

\subsection{Determination of caffeine concentration}

The caffeine concentration in water extract was determined by following the method proposed by Yao et al. (2006). In order to remove the tanines, water extract $(2 \mathrm{~mL}), \mathrm{HCl}$ solution $(0.01 \mathrm{~mol} / \mathrm{L} ; 1 \mathrm{~mL})$ and $\mathrm{Pb}\left(\mathrm{CH}_{3} \mathrm{COO}\right)_{2}$ solution $(1.5 \mathrm{~mol} / \mathrm{L}$; $0.2 \mathrm{~mL}$ ) were mixed and diluted to $25 \mathrm{ml}$ with distilled water. The obtained solution was filtered through Munktell No. 8 filter paper. The filtrate $(5 \mathrm{~mL})$ and $\mathrm{H}_{2} \mathrm{SO}_{4}$ solution $(4.5 \mathrm{~mol} / \mathrm{L}$; $0.02 \mathrm{~mL}$ ) were combined and diluted to $10 \mathrm{ml}$ with distilled water to eliminate excess lead and then filtered using the same type of filter paper. The absorbance $(A b s)$ of the filtrate was measured using a UV-vis spectrophotometer (Agilent technologies, US) at $274 \mathrm{~nm}$. The concentration of caffeine $(\mathrm{C} \mathrm{mg} / \mathrm{L}$ ) was calculated using a standard curve derived from the caffeine $(0-1000 \mathrm{mg} / \mathrm{L})$, with the following equation:

$C=\frac{A b s}{0,0516}+0,004 \quad\left(R^{2}=0.999\right)$

where $\mathrm{R}^{2}$ is the correlation coefficient. For each temperature, the degree of extraction $(\alpha)$ was determined by the equation:

$\alpha=\frac{C}{C_{\max }}$

where $C(\mathrm{mg} / \mathrm{L})$ is the caffeine concentration in water extract in the time interval $t$, and $C_{\max }$ is the maximal concentration of caffeine achieved during the extraction process at a particular temperature.

\subsection{Methods used to evaluate the kinetic model and kinetic parameters}

\subsubsection{Model fitting method}

The kinetic models of the reactions in solid state and in the interface of the solid-solution are derived from a number of presumptions about the mechanisms of the process. The model fitting method is based on fitting the obtained data into various known solid state reaction models.

The selection of the kinetic equation for fitting the experimental data was performed using the model fitting method (Brown et al., 1980). In accordance with this method, the experimentally obtained curves that describe the dependence of the degree of extraction on time ( $\alpha=f(t)$, conversation curve) were transformed into a normalized conversation curve $\alpha=f\left(t_{n}\right)$, where $t_{\mathrm{n}}$ is the normalized time, defined by the equation:

$t_{n}=\frac{t}{t_{0,9}}$

where $t_{0.9}$ is obtained by calculating the time at which the degree of extraction $(\alpha)$ is 0.9 . The kinetic model is determined by analytically comparing (using the sum of squares of the residual) the normalized model conversion curve with the experimentally obtained normalized conversion curve. The chosen kinetic model for fitting the experimental data is the one for which the sum of squares of the deviation of its normalized conversional curve gives minimal values from the experimental normalized conversion curve.

\subsubsection{Differential isoconversional method}

The Friedman isoconversional method (Friedman, 1963) was used to determine the kinetic parameters, activation energy $\left(E_{\mathrm{a}}\right)$ and pre-exponential factor ( $(\mathrm{ln} \mathrm{A})$ of the investigated extraction process of caffeine from guarana for various extraction degrees. According to this method the kinetic analysis of experimental data is based on the following rate equation:

$\frac{d \alpha}{d t}=\operatorname{Af}(\alpha) \exp \left(\frac{E_{\mathrm{a}, a}}{R T}\right)$

where $d \alpha / d t$ is the reaction rate, $T$ is the temperature, $A$ is the pre-exponential factor, $E_{a}$ is the activation energy, $f(\alpha)$ is the general mathematical expression of the kinetic model and $R$ is the gas constant. The logarithm form of Eq. (4) leads to:

$\ln \left(\frac{d \alpha}{d t}\right)=\ln A+\ln f(\alpha)\left(\frac{E_{\mathrm{a}, a}}{R T}\right)$

Accepting that the reaction rate constant is an extent of conversion and only a function of temperature (isoconversional principle of Friedman), Eq. (5) can be written as:

$\ln \left(\frac{d \alpha}{d t}\right)_{\alpha}=\ln \left[A_{\alpha} \cdot f(\alpha)\right]-\left(\frac{E_{a, a}}{R T}\right)$

The plot (ln $d \alpha / d t)$ vs. reciprocal temperature $(1 / T)$ should be a straight line whose slope allows the evaluation of the activation energy for a particular degree of extraction.

\subsubsection{Mathematical modeling of extraction}

There are many mathematical approaches that can be used to describe the kinetics of the solid-liquid extraction process. The most frequently used models are: a) Spiro's steady state kinetic model (Spiro and Jago, 1982); b) film theory (Stanković et al., 1994); and c) unsteady state diffusion through plant material 

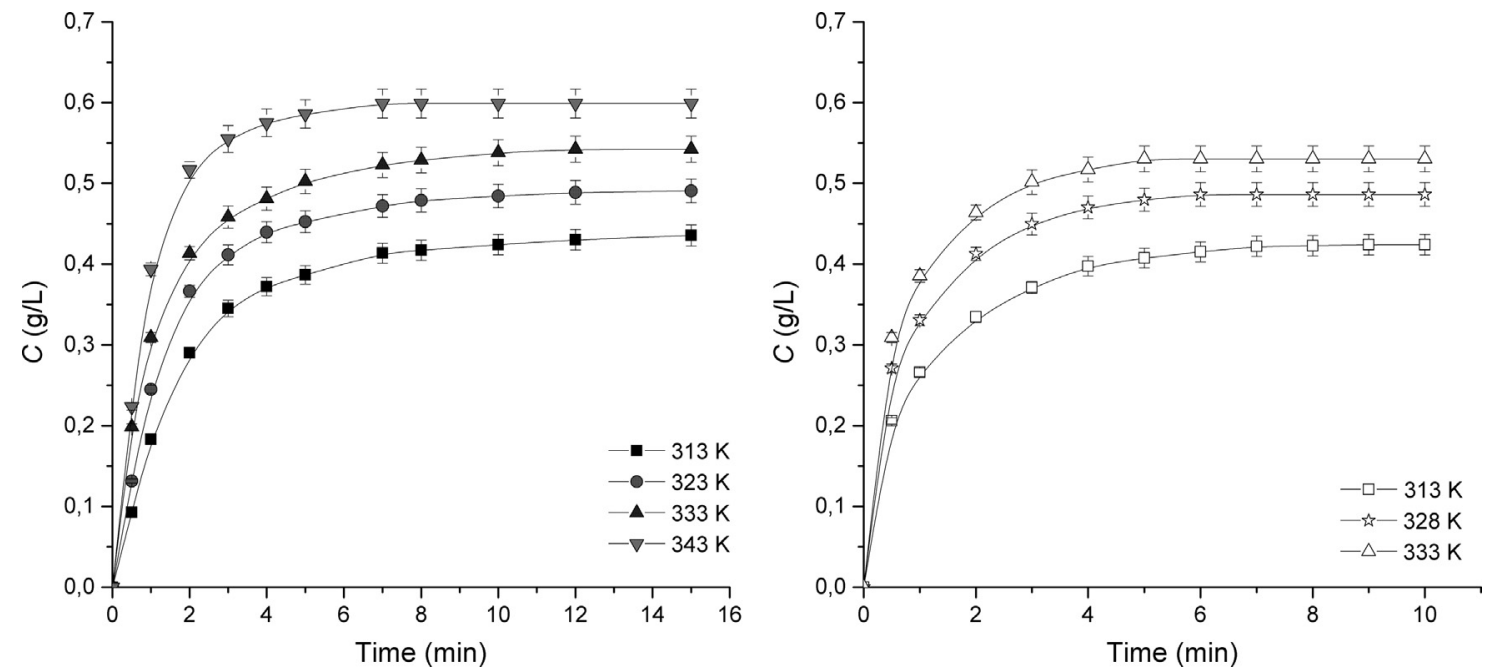

Fig. 2 - The isothermal kinetic curves of extracted caffeine from guarana seed under conventional (a) and microwave heating (b) (results are presented as means \pm standard deviations).

(Ponomaryov, 1976; Veličković et al., 2006; Stanisavljević et al., 2007).

Spiro's steady state kinetic model is expressed by the equation (Spiro and Jago, 1982):

$\ln \left(\frac{C_{\infty}}{C_{\infty}-C}\right)=k_{s} \cdot t+\alpha$

where $C_{\infty}$ is equilibrium concentration of caffeine $(g / L)$ at highest temperature, and $C$ is the concentration of caffeine at time $t(\mathrm{~min}), k_{\mathrm{s}}$ is observed first order rate constant $\left(\mathrm{min}^{-1}\right)$, and $\alpha$ is an integration constant. In the case when the kinetics of the extraction of the caffeine follows first-order behavior, plotting $\ln \left[C_{\infty} /\left(C_{\infty}-C\right)\right]$ versus time will give straight lines, whose slope corresponds to the constant of the caffeine extraction rate.

The film-theory and unsteady state diffusion through plant material are kinetic models derived from Fick's law and are expressed in Eqs. (8) and (9), respectively (Veličković et al., 2006):

Film theory $: \ln \left(1-\frac{C}{C_{S}}\right)=\ln (1-b)-k \cdot t$

Unsteady state diffusion theory $: \ln \left(\frac{q}{q_{0}}\right)=\ln \left(1-b^{\prime}\right)-k^{\prime} \cdot t$

where, $b$ and $b$ ' are washing coefficients according to the film model, the unsteady state diffusion model; $C$ is the concentration of caffeine $(\mathrm{g} / \mathrm{L})$ in liquid extract during the extraction; $C_{\mathrm{s}}$ is maximum concentration of caffeine $(\mathrm{g} / \mathrm{L})$ in a solvent at the highest temperature; $k$ and ' $k$ ' are slow extraction coefficients according to the film model and the unsteady state diffusion model $\left(\mathrm{min}^{-1}\right)$; $q$ is the content of caffeine $(\mathrm{g} / \mathrm{g})$ in plant material during the extraction; $q_{0}$ is the content of caffeine $(\mathrm{g} / \mathrm{g})$ present in plant material; and $t$ is time ( $\mathrm{min})$.

\section{Results and discussion}

The obtained isothermal kinetic curves of the caffeine extraction (dependence of $\mathrm{C}$ vs. time), at different temperatures under conventional and microwave heating are shown in Fig. 2a and b.
The extraction kinetic curves under both conventional and microwave conditions at all of the investigated temperatures have the same shape and it is easy to distinguish three characteristic shapes of changes in the increase of the concentration of extracted caffeine over extraction time: linear, convex and plateau. Initially, the concentration of the caffeine increases rapidly, almost linearly, with time. Further increase of the extraction time leads to a convex-like increase in the concentration of the caffeine which is subsequently followed by the plateau. With the increasing temperature of extraction the duration of linear changes and time required to reach the plateau are decreased. Maximal concentration of caffeine in water solution under both conventional and microwave heating increased with the increase in temperature, which indicate that this is thermally activated process.

For evaluating the degree of kinetic complexity of the researched extraction process, the dependence of the activation energy on the degree of the extraction was determined by applying the Friedman isoconversional method (Eq. (6)). The dependence of $E_{\mathrm{a}}$, versus $\alpha$ is shown on Fig. 3 .

From the results presented in Fig. 3, it can be seen that the value of activation energy is practically independent of the degree of caffeine extraction for both heating modes and

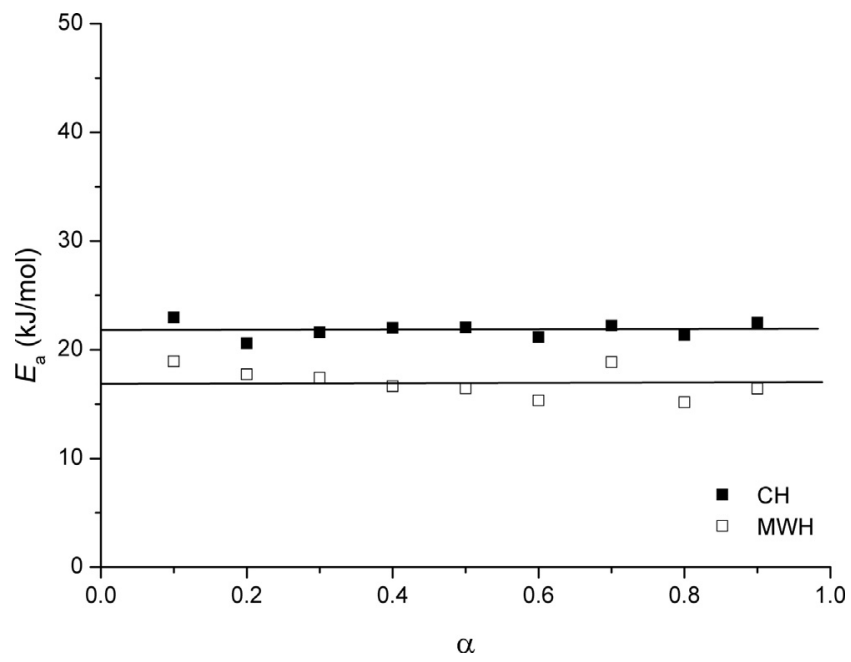

Fig. 3 - The dependence of $E_{a}$, versus the degree of caffeine extraction. 
a)

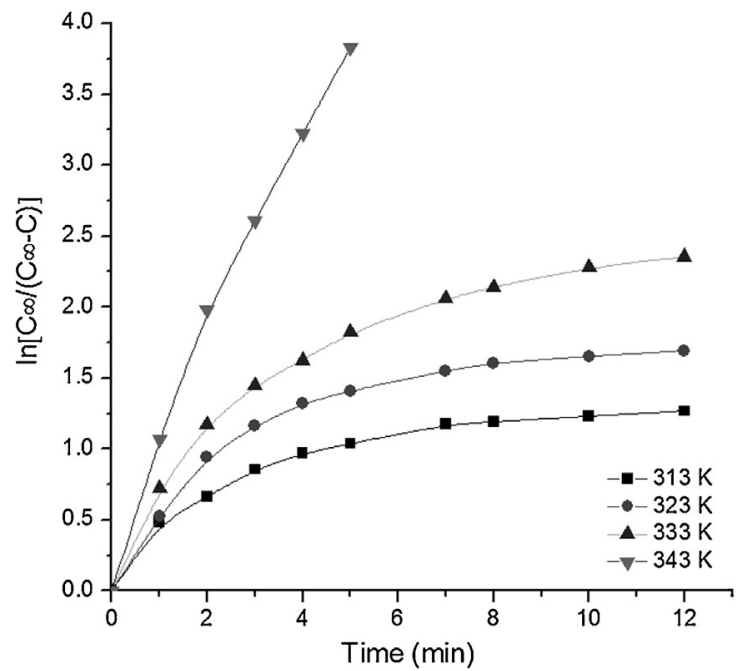

b)

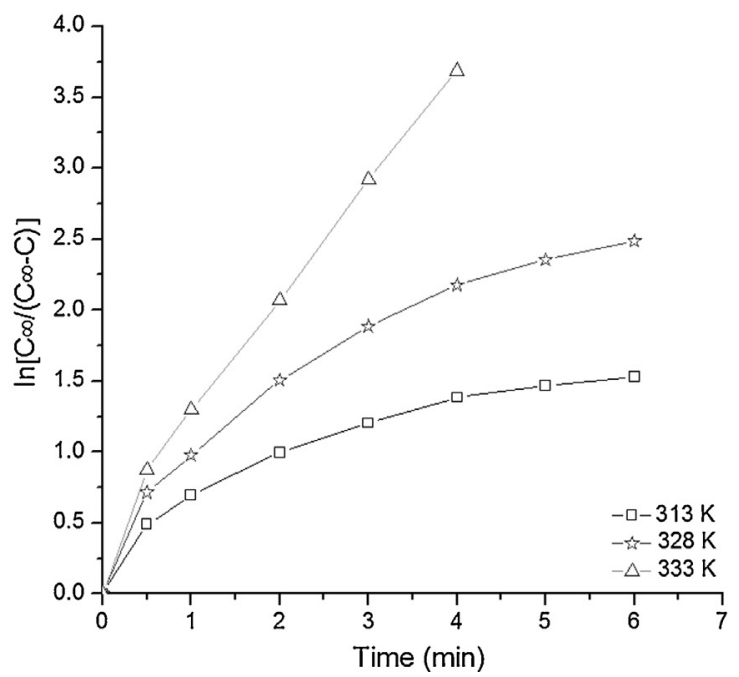

Fig. 4 - The isothermal dependence of $\ln \left[C_{\infty} /\left(C_{\infty}-C\right)\right]$ vs. time of extraction under conventional (a) and microwave heating (b).

a)

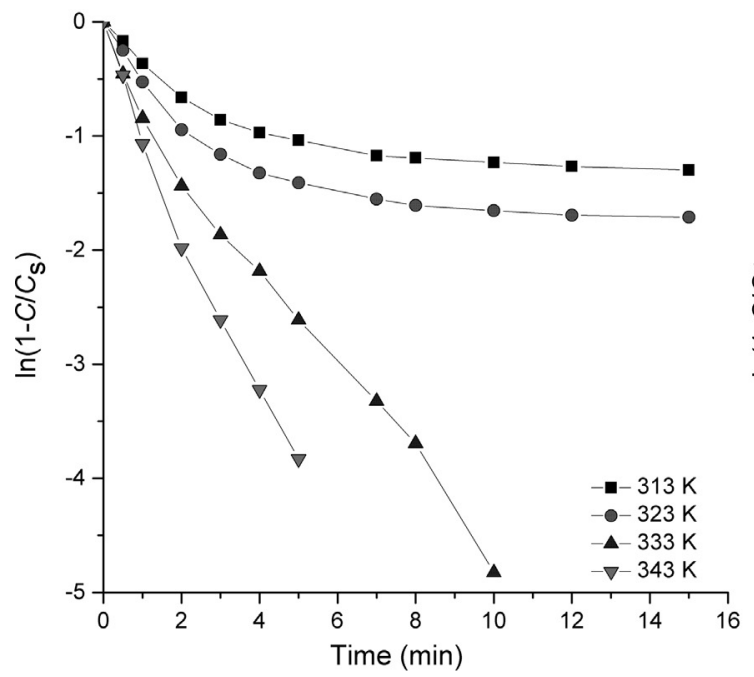

b)

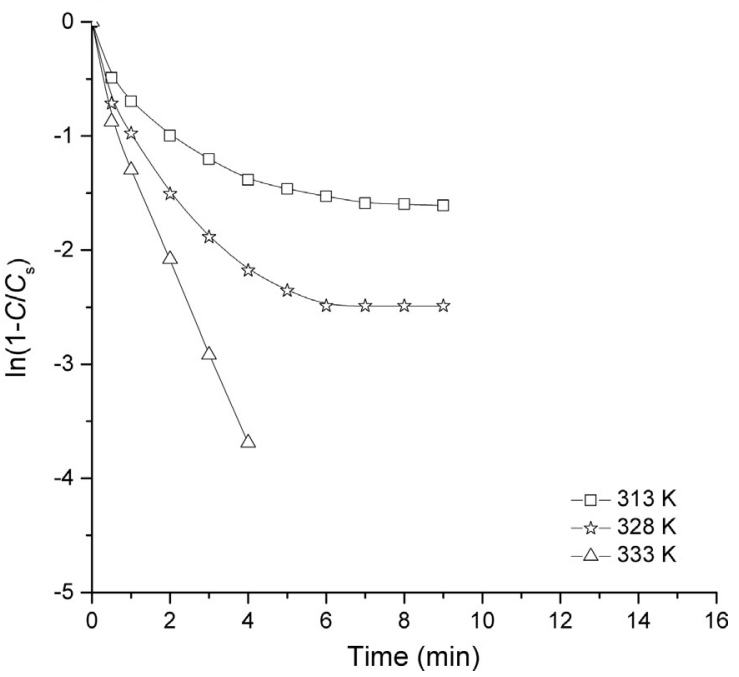

Fig. 5 - The isothermal dependence of $\ln \left[1-C / C_{s}\right]$ vs. time of extraction under conventional (a) and microwave heating (b).

that the values of activation energy for MWH are lower over all degrees of extraction than for $\mathrm{CH}$. Keeping in mind that the $E_{\mathrm{a}}$, is independent of the degree of caffeine extraction, which is typical for the kinetically elementary (single-stage) processes, it can be concluded with a high degree of certainty that the investigated extraction of caffeine presents an elementary kinetic process for both heating modes.

Bearing in mind the nature of the investigated extraction system, the possibilities of using the Spiro's steady state kinetic model (Eq. (7)), film theory (Eq. (8)), and unsteady state diffusion (Eq. (9)), were investigated for modeling the extraction of caffeine from a guarana seed. Fig. 4 shows the isothermal dependence of $\ln \left[C_{\infty} /\left(C_{\infty}-C\right)\right]=f(t)$ at different temperatures, Fig. 5 represents the dependence of $\ln \left[1-C / C_{s}\right]$ on time, and Fig. 6 represents the $\ln \left[q / q_{0}\right]$ on time, at different temperatures.

According to the results presented in Figs. 4-6, none of all three equations fit the experimental data quite well for both conventional and microwave heating mode and at all investigated temperatures. That proves that the kinetics of caffeine extraction cannot be modeled by the proposed Spiro's steady kinetic model, neither by two other kinetic models, film theory and unsteady diffusion through plant material.

Since extraction is a process that takes place at the phase boundary, by application the model fitting method the proper kinetic model of the isothermal caffeine extraction can be obtained. The experimental normalized conversion curves of caffeine extraction under conventional and microwave heating at all of the investigated temperatures were determined and shown in Fig. 7. These curves have an identical shape for all of the investigated temperatures within both heating modes, therefore it was assumed that all of them can be described by the same kinetic model.

By using the model fitting method, it was established with a high degree of certainty $(\geq 0.999)$ that the kinetics of isothermal caffeine extraction under both conventional and microwave heating can be described by Jander theoretical kinetic model (Jander, 1927) of three dimensional diffusion which is given by the following equation:

$$
\left[1-(1-\alpha)^{1 / 3}\right]^{2}=k_{M} \cdot t
$$


a)

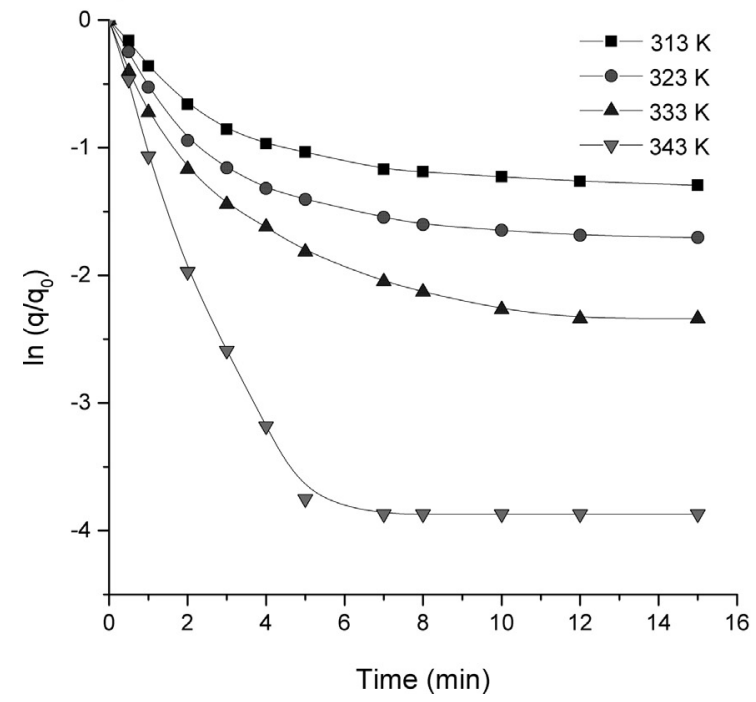

b)

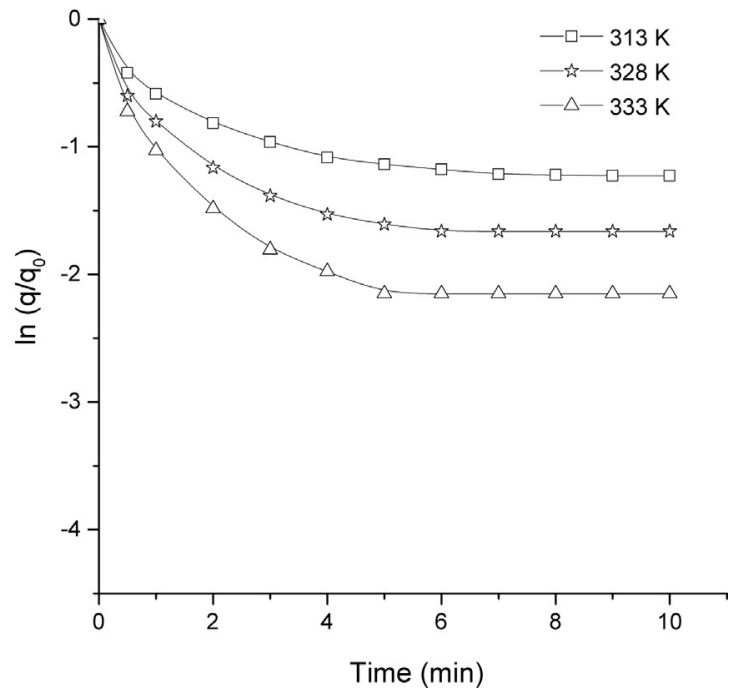

Fig. 6 - The isothermal dependence of $\ln \left[q / q_{0}\right]$ vs. time of extraction under conventional (a) and microwave heating (b).

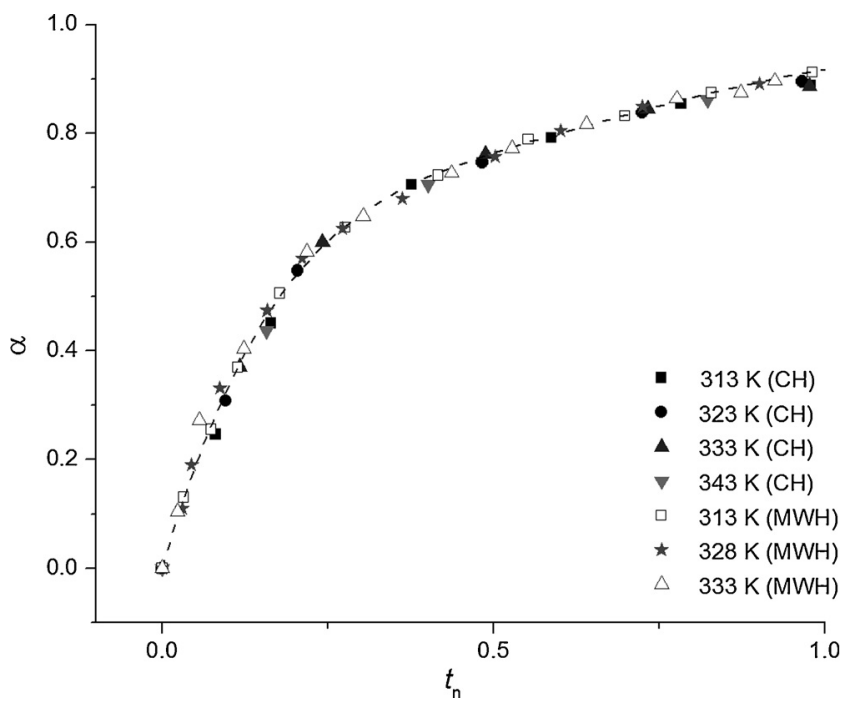

Fig. 7 - Experimental normalized conversion curves of caffeine extraction under conventional and microwave heating.

where, $k_{\mathrm{M}}$ is the model rate constant of caffeine extraction from guarana seed.

When the kinetics of the extraction of caffeine from guarana seed takes place in accordance with the three dimensional diffusion kinetic model, then the dependence of $\left[1-(1-\alpha)^{1 / 3}\right]^{2}$ on time should give straight lines. The isothermal dependence of $\left[1-(1-\alpha)^{1 / 3}\right]^{2}$ versus time of caffeine extraction under conventional and microwave heating is shown in Fig. 8.

As can be seen from Fig. 8, the dependence of $\left[1-(1-\alpha)^{1 / 3}\right]^{2}$ on the extraction time is linear throughout the entire range of caffeine extraction process and at all investigated temperatures for both conventional and microwave heating which confirms that the correct kinetic model was selected for describing the caffeine extraction from guarana seed.

The calculated values of the kinetic parameters and the established mathematical model of kinetic extraction under conventional and microwave conditions enabled the defining of the following model mechanism of the kinetics of extraction of caffeine from solid particles of guarana using the selective solvent: a) The solid component (powder) consists of " $n$ " equal spherical particles of the initial radius $(R)$.

b) Water very quickly diffuses to and on a particle surface due to its small external diffusion resistance and creates extracted layer on the particle.

c) Formation of extracted layer on the particle surface does not hinder the diffusion, and water extract quickly diffuses into solute.

d) The rate of the extraction of caffeine with water is higher than the rate of transport of water to caffeine molecule in the guarana particle.

e) The diffusion coefficient of water does not change with time.

f) The rate limiting step of extraction of caffeine from guarana particle is rate of growth of extracted layer thickness.

g) The rate growth of extracted layer thickness is proportional to the diffusion coefficient $(D)$ of water and inversely proportional to the extracted layer thickness $(x)$.

$\frac{d x}{d t}=k \frac{D}{x}$

where $k$ is a constant dependent on the nature of the solid and liquid phases and conditions.

By integrating Eq. (11) with boundaries for $x$ from $x=0$ to $x=x$ and for time from $t=0$ to $t=t$, we come to the Jander expression for the parabolic growth of extracted layer:

$x^{2}=2 k D t$

In that case, the degree of extraction $(\alpha)$ is given by the equation:

$\alpha=\frac{\frac{4}{3} n \rho \pi R^{3}-\frac{4}{3} n \rho \pi(R-x)^{3}}{\frac{4}{3} n \rho \pi R^{3}}$

where $\rho$ is density of the guarana seed particle. Eq. (13) can be easily transformed into:

$\alpha=1-\left(\frac{R-x}{R}\right)^{3}$ 

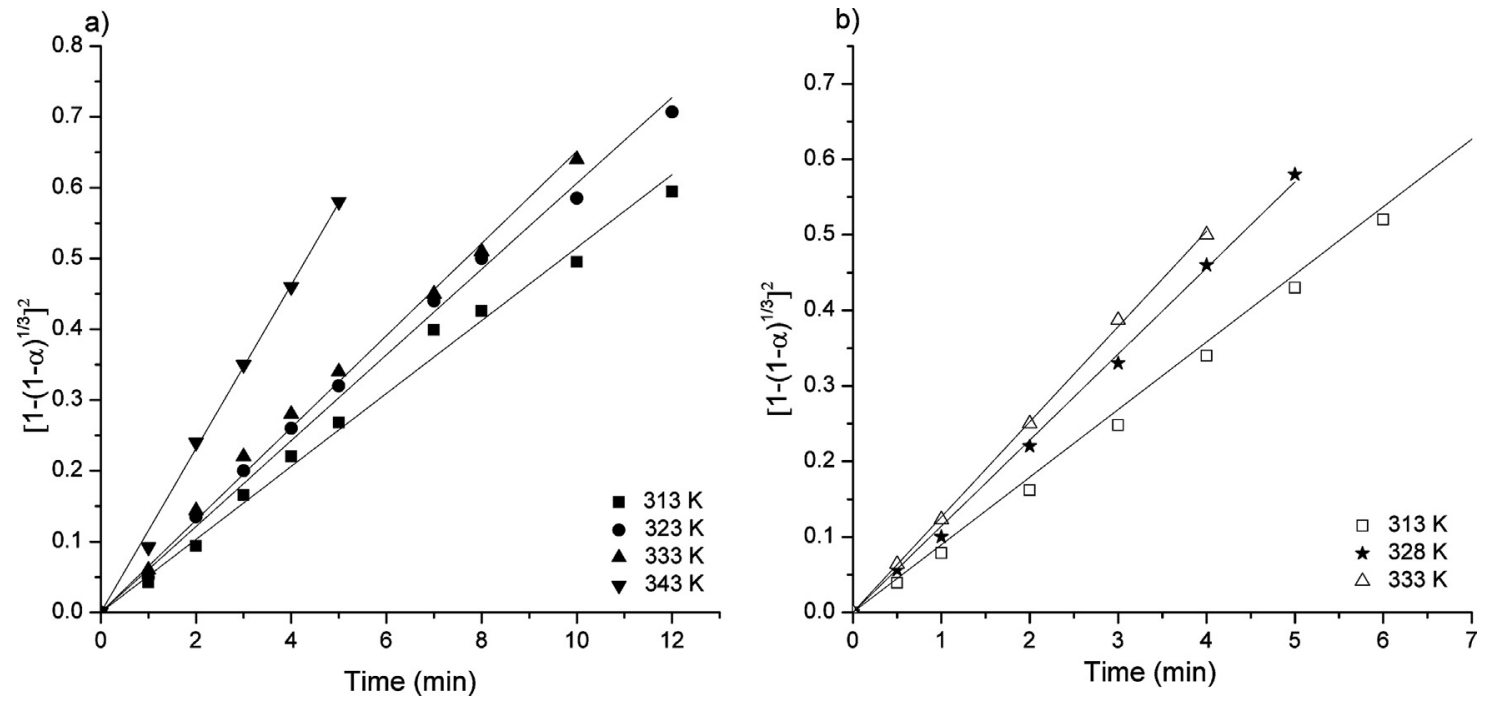

Fig. 8 - The isothermal dependence of $\left[1-(1-\alpha)^{1 / 3}\right]^{2}$ vs. time of caffeine extraction under conventional (a) and microwave heating (b).

The rearrangement of Eq. (14) leads to the definition of $x$ :

$x=R\left[1-(1-\alpha)^{1 / 3}\right]$

Bearing in mind that $x^{2}=2 k D t$, substituting Eq. (12) into Eq. (15) gives:

$R^{2}\left[1-(1-\alpha)^{1 / 3}\right]^{2}=2 k D t$

or:

$\left[1-(1-\alpha)^{1 / 3}\right]^{2}=\frac{2 k D}{R^{2}} \cdot t=k_{M} \cdot t$

where $k_{\mathrm{M}}=2 \mathrm{kD} / \mathrm{R}^{2}$.

The mathematical identity of Eq. (17) with the established kinetic model of extraction approved the physical objectivity of the proposed kinetic model of extraction. Based on that, we can claim that the rate limiting step of the extraction process is rate growth of extracted layer thickness and that the model rate constant $k_{\mathrm{M}}$ is linearly dependent on the diffusion coefficient $D$ and inversely dependent on the $R^{2}$.

The determined kinetic model of the extraction of caffeine shows that the rate limiting step of extraction process under both heating modes is rate growth of the layer thickness. This allows the calculation of the model rate constant $\left(k_{\mathrm{M}}\right)$, and kinetic parameters, namely, activation energy $\left(E_{\mathrm{a}}\right)$ and pre-exponential factor $(\ln \mathrm{A})$ for the investigated extraction process. Since $k_{\mathrm{M}}$ value increases with the temperature increase, the model parameters of caffeine extraction $\left(E_{\mathrm{a}}\right.$ and $\ln A$ ) were determined by applying the Arrhenius equation. These results are given in Table 1.

The calculated values of the model rate constant of caffeine extraction under microwave heating are higher than those under conventional heating at the same temperature. The value of activation energy for the investigated temperature range under conventional heating is $E_{\mathrm{a}}{ }^{\mathrm{CH}}(\mathrm{kJ} / \mathrm{mol})=21.80 \pm 1.2$, which is higher than the value of activation energy for the same process under microwave heating. Also, this value is slightly higher in comparison to the value of $E_{a}$ reported by Spiro et al. (1992) for diffusion caffeine in water, which was found to be $17.3 \mathrm{~kJ} / \mathrm{mol}$.
Table 1 - The influence of temperature on model rate constant of caffeine extraction and kinetic parameters $\left(E_{\mathrm{a}}\right.$ and $\left.\ln \mathrm{A}\right)$.

\begin{tabular}{|c|c|c|c|}
\hline \multicolumn{2}{|c|}{ Microwave heating } & \multicolumn{2}{|c|}{ Conventional heating } \\
\hline $\mathrm{T}(\mathrm{K})$ & $k_{\mathrm{M}}{ }^{\mathrm{MWH}}\left(\min ^{-1}\right)$ & $\mathrm{T}(\mathrm{K})$ & $k_{\mathrm{M}}{ }^{\mathrm{CH}}\left(\min ^{-1}\right)$ \\
\hline 313 & $0.085 \pm 0.002$ & 313 & $0.0515 \pm 0.001$ \\
\hline 328 & $0.114 \pm 0.001$ & 323 & $0.0606 \pm 0.001$ \\
\hline 333 & $0.126 \pm 0.001$ & 333 & $0.0651 \pm 0.001$ \\
\hline & & 343 & $0.1156 \pm 0.002$ \\
\hline
\end{tabular}

Kinetic parameters

Microwave heating Conventional heating

$\overline{E_{\mathrm{a}}{ }^{\mathrm{MWH}}(\mathrm{kJ} / \mathrm{mol})} \quad \overline{\ln \mathrm{A}^{\mathrm{MWH}}\left(\mathrm{min}^{-1}\right)} \quad \overline{E_{\mathrm{a}}{ }^{\mathrm{CH}}(\mathrm{kJ} / \mathrm{mol})} \quad \ln \mathrm{A}^{\mathrm{CH}}\left(\mathrm{min}^{-1}\right)$

$\begin{array}{llll}17.10 \pm 0.12 & 4.11 \pm 0.04 & 21.80 \pm 1.2 & 6.6 \pm 0.7\end{array}$

The value of activation energy for the investigated temperature range under microwave heating is $E_{\mathrm{a}}{ }^{\mathrm{MWH}}$ $(\mathrm{kJ} / \mathrm{mol})=17.10 \pm 0.12$, which is slightly higher in comparison to the values of the activation energy reported by Spigno and De Faveri (2009) for the non-isothermal microwave-assisted extraction of total phenols and caffeine from black tea, which was found to be $14.63 \mathrm{~kJ} / \mathrm{mol}$ in temperature range from 328-363 K. Linares et al. (2010) reported similar results of $E_{a}$, which was found to be $14.26 \mathrm{~kJ} / \mathrm{mol}$, for extracting total water soluble solids from yerba mate leaves in the temperature range from $313-343 \mathrm{~K}$. Furthermore, the calculated $E_{\mathrm{a}}$ value for the caffeine extraction under microwave heating is slightly lower, and $E_{\mathrm{a}}$ value for conventional heating is slightly higher than the measured value of activation energy for the diffusion of water molecule $\left(E_{\mathrm{a}}=18.8 \mathrm{~kJ} / \mathrm{mol}\right)$ provided by Eisenberg and Kauzmann (2005). This indicates that the structure of the extraction layer on the guarana powder particle is very open and allows easy transport of water to the caffeine molecule and also easy transport of the water extract of caffeine from the guarana particle under both heating modes.

The established kinetics elementarity of the caffeine extraction under the $\mathrm{MWH}$, the kinetic model of extraction and the calculated values of the constant rates and kinetic parameters enabled a conclusion whether the increase of the extraction rate under the $\mathrm{MWH}$ was a consequence of overheating or specific microwave effects. Keeping in mind that the 
Arrhenius equation is still valid for microwave heated extraction, based on the known values of the constant rate under MWH $\left(k_{\mathrm{M}}{ }^{\mathrm{MWH}}\right)$ and the constant rate for conventional heating $\left(k_{\mathrm{M}}{ }^{\mathrm{CH}}\right)$ (Adnadjević and Jovanović, 2010, 2011) the degree of increasing the isothermal constant rate of caffeine extraction for $\mathrm{MWH}(\mathrm{K})$ can be calculated:

$K=\frac{k_{M}{ }^{M W H}}{k_{M}{ }^{C H}}=\frac{A^{M W H} \exp \left(-E_{a}{ }^{M W H} / R T_{M W H}\right)}{A^{C H} \exp \left(-E_{a}{ }^{C H} / R T\right)}$

where $E_{\mathrm{a}}{ }^{C H}$ and $E_{\mathrm{a}}{ }^{\mathrm{MWH}}$ is activation energy under the conditions of conventional and microwave heating and $\mathrm{A}^{\mathrm{CH}}$ and $A^{M W H}$ is the pre-exponential factor under the conditions of conventional and microwave heating. The degree of increasing the isothermal constant rate of caffeine extraction is calculated to be 1.650 for $313 \mathrm{~K}$, and 1.938 for $333 \mathrm{~K}$, respectively.

In the case when the increase in the rate of extraction under the MWH would occur due to overheating, it would be: $E_{\mathrm{a}}{ }^{\mathrm{CH}}=E_{\mathrm{a}}{ }^{\mathrm{MWH}}$ and $\mathrm{A}^{\mathrm{CH}}=\mathrm{A}^{\mathrm{MWH}}$. Based on Eq. (18) it is possible to find the temperature at which the process would occur under MWH (T $\left.T_{M W H}\right)$, (Eq. (19)):

$\mathrm{T}_{\mathrm{MWH}}=\frac{E_{\mathrm{a}}{ }^{\mathrm{CH}} \cdot \mathrm{T}}{E_{\mathrm{a}}{ }^{\mathrm{CH}}-\mathrm{RT} \ln \mathrm{K}}$

where $\mathrm{T}$ is experimental measured value of microwave temperature.

Since the calculated values of $\mathrm{T}_{\mathrm{MWH}}$, are on average $20-31 \mathrm{~K}$ higher than the actually measured values of the average temperature (for $\mathrm{T}=313 \mathrm{~K}, \mathrm{~T}_{\mathrm{MWH}}=333 \mathrm{~K}$, and for $\mathrm{T}=333 \mathrm{~K}, \mathrm{~T}_{\mathrm{MWH}}=364 \mathrm{~K}$ ), it can be concluded that the extraction rate increase under $\mathrm{MWH}$ is not a consequence of overheating, but a result of specific microwave effects, which leads to the change in the values of kinetic parameters, $E_{\mathrm{a}}$ and $\ln A$ in the case of MWH. The established decrease in the values of activation energy and $\ln \mathrm{A}$ under $\mathrm{MWH}$ compared to the $\mathrm{CH}$ permits the possibility of a new explanation of the influence of MWH on the kinetics of isothermal extraction of caffeine. This explanation is based on the integration of Larsson model of activating the molecule via selective energy transfer (SET model) (Larsson, 1989) and Linert concept of isokinetic temperature (Linert and Jameson, 1989). The basic assumptions of the SET model are: a) there is the possibility of coupling between vibration modes of caffeine molecule $(v)$ and vibration modes of reaction system (solvent) $(\omega)$; b) the activated complex of extraction process arises from resonant (selective) transfer of required energy from solvent to resonant vibration mode of caffeine (v); c) the value of transferred energy is quantized and it is determined by the number of resonant vibration quanta (n); d) due to the transfer of energy there is a change in the value of anharmonicity factor of the resonant vibration mode.

Based on the above assumptions, in accordance with the SET model, it is possible to obtain the expression for the extraction rate constant and isokinetic temperature $\left(T_{i c}\right)$. Treating this resonance system as a classical forced damped harmonic oscillator, an empirical Arrhenius equation can be obtained:

$\ln k=\ln A+\frac{\omega}{v^{2}-\omega^{2}}\left[ \pm \frac{\pi}{2}-\operatorname{arctg} \frac{v \omega}{2\left(v^{2}-\omega^{2}\right)}\right] \frac{\sum_{\mathrm{i}} \Delta E_{\mathrm{i}}}{h c}-\frac{E_{\mathrm{a}}}{R T}$

where $\Delta E \mathrm{i}=h c v_{i}$ is the energy increment between the two levels $n_{i}$ and $n_{i+1}, h$ is the Planck constant and $c$ is the velocity of
Table 2 - The values of $v, n$ and $x$ for caffeine extraction under $\mathbf{C H}$ and $\mathbf{M W H}$.

\begin{tabular}{lll} 
Variable & \multicolumn{1}{c}{ CH } & MWH \\
\hline$\nu\left(\mathrm{cm}^{-1}\right)$ & 317 & 317 \\
$n$ & 6 & 4 \\
$x$ & -0.028 & -0.012 \\
\hline
\end{tabular}

light. As $n \sum_{i} \Delta E_{i}=E_{a}$, Eq. (20) can be rewritten in the following form:

$\ln k=\ln A+\frac{E_{\mathrm{a}}}{R}\left(\frac{1}{\mathrm{~T}_{\mathrm{ic}}}-\frac{1}{\mathrm{~T}}\right)$

where isokinetic temperature $\left(T_{i c}\right)$ is given with the expression:

$\mathrm{T}_{\mathrm{ic}}=\frac{N h c}{\mathrm{R}} \frac{v^{2}-\omega^{2}}{\omega} \frac{1}{ \pm \frac{\pi}{2}-\operatorname{arctg} \frac{v \omega}{2\left(v^{2}-\omega^{2}\right)}}$

where $\mathrm{N}$ is Avogadro's number.

For resonance conditions, $\omega=v$, so Eq. (22) can be transformed to:

$\mathrm{T}_{\mathrm{ic}}=\frac{\mathrm{Nhcv}}{2 \mathrm{R}}=0.715 v$

when $v$ is given in $\mathrm{cm}^{-1}$ and $\mathrm{T}_{\mathrm{ic}}$ is in $\mathrm{K}$.

In accordance with Linert concept (Linert and Jameson, 1989), isokinetic temperature is in a relationship with some form of the equation of compensation effect by the expression:

$\mathrm{T}_{\mathrm{ic}}=\frac{1}{\mathrm{R} \cdot \mathrm{b}}$

where $\mathrm{R}$ is gas constant given in $\mathrm{kJ} / \mathrm{mol}$ and $\mathrm{b}$ is the slope of compensation Eq. (25):

$\ln A_{F}=a+b \cdot E_{a, F}$

where $a$ is the parameter of the compensation equation, and $E_{\mathrm{a}, \mathrm{F}}$ and $\ln A_{\mathrm{F}}$ are the activation energy and pre-exponential factor in a defined physical field (thermal or microwave).

Therefore, if there is compensation equation which connects the values of the kinetic parameters $\left(E_{\mathrm{a}}, \ln A\right)$ calculated under different heating conditions ( $\mathrm{CH}$ and $\mathrm{MWH})$, it is possible to calculate $T_{\mathrm{ic}}$ and $v$, based on the known value of $b$. There is a functional relationship between the calculated values of the kinetic parameters of extraction under conventional and microwave heating, which is expressed as:

$\ln \mathrm{A}_{\mathrm{F}}=-4.95+0.53 \mathrm{E}_{\mathrm{a}, \mathrm{F}}$

Therefore, it is possible to calculate $T_{\text {ic }}$ and $v$, based on the known value of $b=0.53 \mathrm{~mol} / \mathrm{kJ}$ (Table 2 ).

As the value of activation energy is in accordance with Larson model given by the equation:

$E_{\mathrm{a}}=h v \cdot(1+n x)+R T$

where $x$ is the anharmonicity parameter and $n$ is the vibration quantum number. When $E_{\mathrm{a}}$ values of particular elementary stages of extraction are known, it is possible to determine the values of $n$ and $x$ using Eq. (27).

The values of $v, n$ and $x$ for extraction under microwave and conventional heating are given in Table 2. 
Based on the results given in Table 2, it is possible to conclude that microwave heating does not lead to changes in the mechanism of the activation of caffeine molecule. Activation under $\mathrm{MWH}$ and $\mathrm{CH}$ is performed by an identical mechanism, with resonant transfer of required energy $\left(E_{\mathrm{a}}\right)$ from solvent to the resonant vibration mode of caffeine molecule with the wave number of resonant vibrations, $v=317 \mathrm{~cm}^{-1}$ which corresponds to the intermolecular vibration of the $\mathrm{N}_{3}-\mathrm{CH}_{3}$ band of caffeine molecule (Srivastava and Singh, 2013; Nolasco et al., 2006). Therefore, the activation of the caffeine molecules for the extraction process begins with the selective transfer of activation energy from solvent to the resonant vibration mode of the $\mathrm{N}_{3}-\mathrm{CH}_{3}$ band of caffeine molecule whose energy is increasing and that is extended and allows the release of caffeine from the particles of guarana. The number of resonant quanta required for the activation of caffeine molecule under $\mathrm{MWH}$ is lower than the number of quanta under $\mathrm{CH}$. The decreased value of the quanta number necessary for the activation of caffeine molecule under microwave conditions is most likely caused by the increased energy of the ground vibration level of resonant oscillator in caffeine molecule due to the absorption of microwave energy. This leads to an increase in extraction rate, decrease in $E_{\mathrm{a}}$ and $\ln A$, and increase in anharmonicity factor under microwave conditions compared to conventional conditions.

\section{Conclusion}

The rate of the extraction of caffeine under MWH is $\sim 2$ times higher than under $\mathrm{CH}$. The isothermal extraction of caffeine from a guarana seed powder with water is an elementary kinetic process in both conventional and microwave heating mode. The established values of Arrhenius kinetics parameters under $\mathrm{MWH}$ are lower than the kinetics parameters values under $\mathrm{CH}$. The effects of MWH on the kinetics of the extraction of caffeine from guarana seed are explained by using the SET model of the formation of activation complexes. It is shown that the activation of caffeine molecules for both $\mathrm{MWH}$ and $\mathrm{CH}$ is performed by an identical mechanism, by a resonant selective transfer of energy from solvent to the caffeine molecule. The selective transfer of energy occurs at resonant frequency with the wave number, $v=317 \mathrm{~cm}^{-1}$, which corresponds to the intermolecular vibration of the $\mathrm{N}_{3}-\mathrm{CH}_{3}$ band of caffeine molecule. The activation energy of the extraction process is a quantized value and is predetermined by a number of the resonant quanta which are selectively transferred from solvent to the resonant oscillator of caffeine molecule.

\section{Acknowledgement}

The investigation was supported by the Ministry of Science and Technical Development of the republic of Serbia, through Project No.172015 OI.

\section{References}

Adnadjević, B., Jovanović, J., 2010. Isothermal dehydration of the poly(acrylic-co-methacrylic acid) hydrogel. Ind. Eng. Chem. Res. 49, 11708-11713.

Adnadjević, B., Jovanović, J., 2011. The effect of microwave heating on the isothermal kinetics of chemicals reaction and physicpchemical processes. In: Grundas, S. (Ed.), Advances in Induction and Microwave Heating of Mineral and Organic Materials. INTECH, Open Access Publisher.
Beck, H.T., 2005. Caffeine, alcohol, and sweeteners. In: Prance, G.T. (Ed.), The Cultural History of Plants. Routledge, New York.

Boussetta, N., Vorobiev, E., Deloison, V., Pochez, F., Falcimaigne-Cordin, A., Lanoisellé, J.L., 2011. Valorisation of grape pomace by the extraction of phenolic antioxidants: application of high voltage electrical discharges. Food Chem. 128, 364-370

Brown, M.E., Dollimore, D., Galway, A.K., 1980. Reactions in the solid state. In: Bamford, C.H., Tipper, C.F. (Eds.), Comprehensive Chemical Kinetics. Elsevier, Amsterdam.

Chen, Y., Xie, M.Y., Gong, X.F., 2007. Microwave-assisted extraction used for the isolation of total triterpenoid saponins from Ganoderna atrum. J. Food Eng. 81, 162-170.

Eisenberg, D.S., Kauzmann, W., 2005. The structure and properties of water. Oxford University Press USA.

Friedman, H., 1963. Kinetics of thermal degradation of char-forming plastics from thermogravimetry. Applications to a phenol plastic. J. Polym. Sci. 6C, 183-195.

González-Nuñez, L.N., Cañizares-Macías, M.P., 2011. Focused microwaves-assisted extraction of theobromine and caffeine from cacao. Food Chem. 129, 1819-1824.

Hemwimon, S., Pavasant, P., Shotipruk, A., 2007. Microwave-assisted extraction of antioxidative anthraquinones from roots of Morinda citrifolia. Sep. Purif. Technol. 54, 44-50

Hoz, A., Diaz-Ortiz, A., Moreno, A., 2005. Microwaves in organic synthesis. Thermal and non-thermal microwave effects. Chem. Soc. Rev. 34, 164-178.

Jaganyi, D., Price, R.D., 1999. Kinetics of tea infusion: the effect of the manufacturing process on the rate of extraction of caffeine. Food Chem. 64, 27-31.

Jafari, M.T., Rezaei, B., Javaheri, M., 2011. A new method based on electrospray ionization ion mobility spectrometry (ESI-IMS) for simultaneous determination of caffeine and theophylline. Food Chem. 126, 1964-1970.

Jander, W., 1927. Reaktionen im festen zustande bei höheren temperaturen. II: Mitteilung. 341 reaktionsgeschwindigkeiten exotherm verlaufender umsetzungen. Zeitschrift für anorganische 342 und allgemeine Chemie 166, 31-52.

Jun, X., 2009. Caffeine extraction from green tea leaves assisted by high pressure processing. J. Food Eng. 94, 105-109.

Kaufmann, B., Christen, P., 2002. Recent extraction techniques for natural products: microwave-assisted extraction and pressurised solvent extraction. Phytochem. Anal. 13, 105-113.

Linares, A.R., Hase, S.L., Vergara, M.L., Resnik, S.L., 2010. Modeling yerba mate aqueous extraction kinetics: Influence of temperature. J. Food Eng. 97, 471-477.

Larsson, R., 1989. A model of selective energy transfer at the active site of the catalyst. J. Mol. Catal. 55, 70-83.

Lou, Z., Er, C., Li, J., Wang, H., Zhu, S., Sun, J., 2012. Removal of caffeine from green tea by microwave-enhanced vacuum ice water extraction. Anal. Chim. Acta 716, 49-53.

Linert, W., Jameson, R.F., 1989. The isokinetic relationship. Chem. Soc. Rev. 18, 477-505.

Mehr, C.B., Biswal, R.N., Collins, J.L., 1996. Supercritical carbon dioxide extraction of caffeine from guarana. J. Supercrit. Fluids 9, 185-191.

Nolasco, M.M., Amado, A.M., Ribeiro-Claro, P.J., 2006. Computationally-assisted approach to the vibrational spectra of molecular crystals: study of hydrogen-bonding and pseudo-polymorphism. ChemPhysChem 7, 2150-2161.

Pan, X., Niu, G., Liu, H., 2003. Microwave-assisted extraction of tea polyphenols and tea caffeine from green tea leaves. Chem. Eng. Process. 42, 129-133.

Pan, Z., Qu, W., Ma, H., Atungulu, G.G., McHugh, T.H., 2012. Continuous and pulsed ultrasound-assisted extractions of antioxidants from pomegranate peel. Ultrason. Sonochem. 19, 365-372.

Peleg, M., 1988. An empirical model for the description of moisture sorption curves. J. Food Sc. 53, 1216-1219.

Ponomaryov, V.D., 1976. Medicinal Herbs Extraction. Medicina, Moscow (in Russian). 
Rahim, A.A., Nofrizal, S., Saad, B., 2014. Rapid tea catechins and caffeine determination by HPLC using microwave-assisted extraction and silica monolithic column. Food Chem. 147, 262-268.

Rakotondramasy-Rabesiaka, L., Havet, J.L., Porte, C., Fauduet, H., 2007. Solid-liquid extraction of protopina from Fumaria officinalis L.-analysis determination, kinetics reaction and model building. Sep. Purif. Technol. 54, 253-261.

Rostagno, M.A., Manchón, N., D’Arrigo, M., Guillamón, E., Villares, A., García-Lafuente, A., Ramos, A., Martínez, J.A., 2011. Fast and simultaneous determination of phenolic compounds and caffeine in teas mate, instant coffee, soft drink and energetic drink by high-performance liquid chromatography using a fused-core column. Anal. Chim. Acta 685, 204-211.

Saldaña, M.D.A., Zetzl, C., Mohamed, R.S., Brunner, G., 2002. Decaffeination of guarana seeds in a microextraction column using water-saturated $\mathrm{CO}_{2}$. J. Supercrit. Fluids 22, 119-127.

Senol, A., Aydin, A., 2006. Solid-liquid extraction of caffeine from tea waste using battery type extractor: process optimization. J. Food Eng. 75, 565-573.

Sereshti, H., Samadi, S., Jalali-Heravi, M., 2013. Determination of volatile components of green, black, oolong and white tea by optimized ultrasound-assisted extraction-dispersive liquid-liquid microextraction coupled with gas chromatography. J. Chromatogr. A 1280, 1-8.

Sereshti, H., Samadi, S., 2014. A rapid and simple determination of caffeine in teas coffees and eight beverages. Food Chem. 158, 8-13.

Spigno, G., De Faveri, D.M., 2009. Microwave-assisted extraction of tea phenols: a phenomenological study. J. Food Eng. 93, 210-217.

Spiro, M., Jago, D.S., 1982. Kinetics and equilibria of tea infusion. Part 3. Rotating disc experiments interpreted by a steady-state model. J. Chem. Soc. Faraday Trans. 1 78, 295-305.

Spiro, M., Jaganyi, D., Broom, M.C., 1992. Kinetics and equilibria of tea infusion: Part 9. The rates and temperature coefficients of caffeine extraction from green Chun Mee and black Assam Bukial teas. Food Chem. 45, 333-335.

Srivastava, S.K., Singh, V.B., 2013. Ab initio and DFT studies of the structure and vibrational spectra of anhydrous caffeine. Spectrochim. Acta Part A 115, 45-50.
Stanisavljević, I., Lazić, M., Veljković, V., 2007. Ultrasonoc extraction of oil from tobacco (Nicotiana tabacum L.) seeds. Ultrason. Sonochem. 14, 646-652.

Stanković, M.Z., Cakić, M.D., Cvetkovic, D.M., Veljkovic, V.B., 1994. Kinetics of extraction of resinoids from overground parts of sweet clover (Melilotus officinalis L.). J. Serb. Chem. Soc. 59, 735-741.

Stapley, A.G.F., 2002. Modelling the kinetics of tea and coffee infusion. J. Sci. Food Agric. 82, 1661-1671.

Tello, J., Viguera, M., Calvo, L., 2011. Extraction of caffeine from Robusta coffee (Coffea canephora var. Robusta) husks using supercritical carbon dioxide. J. Supercrit. Fluids 59, 53-60.

Veličković, D.T., Milenović, D.M., Ristić, M.S., Veljković, V.B., 2006. Kinetics of ultrasonic extraction of extractive substances from garden (Salvia officinalis L.) and glutinous (Salvia glutinosa L.) sage. Ultrason. Sonochem. 13, 150-156.

Vuong, Q.V., Tan, S.P., Stathopoulos, C.E., Roach, P.D., 2012. Improved extraction of green tea components from teabags using the microwave oven. J. Food Compos. Anal. 27, 95-101.

Wang, H., Helliwell, K., 2000. Epimerisation of catechins in green tea infusions. Food Chem. 70, 337-344.

Wang, H., Chen, L., Xu, Y., Zeng, Q., Zhang, X., Zhao, Q., Ding, L., 2011. Dynamic microwave-assisted extraction coupled on-line with clean-up for determination of caffeine in tea. LWT Food Sci. Technol. 44, 1490-1495.

Wang, L., Gong, L.H., Chen, C.J., Han, H.B., Li, H.H., 2012. Column-chromatographic extraction and separation of polyphenols caffeine and theanine from green tea. Food Chem. 131, 1539-1545.

Xiao, W., Han, L., Shi, B., 2008. Microwave-assisted extraction of flavonoids from Radix Astragali. Sep. Purif. Technol. 62, 616-620.

Yao, L.H., Liu, X., Jiang, Y., Caffin, N., D’Arcy, B., Singanusong, R., et al., 2006. Compositional analysis of teas from Australian supermarkets. Food Chem. 94, 115-122.

Zhang, B., Yang, R., Liu, C.Z., 2008. Microwave-assisted extraction of chlorogenic acid from flower buds of Lonicera japonica Thunb. Sep. Purif. Technol. 62, 480-483.

Ziaedini, A., Jafari, A., Zakeri, A., 2010. Extraction of antioxidants and caffeine from green tea (Camelia sinensis) leaves: kinetics and modeling. Food Sci. Technol. Int. 16, 505-510. 